Hydrological Research Letters 5, 88-92 (2011)

Published online in J-STAGE (www.jstage.jst.go.jp/browse/HRL). DOI: 10.3178/HRL.5.88

\title{
Spatial variations in evapotranspiration over East Asian forest sites. II. Surface conductance and aerodynamic conductance
}

\author{
Rehana Khatun', Takeshi Ohta ${ }^{1}$, Ayumi Kotani ${ }^{1}$, Jun Asanuma², Minoru Gamo ${ }^{3}$, Shijie Han ${ }^{4}$, \\ Takashi Hirano ${ }^{5}$, Yuichiro Nakai ${ }^{6}$, Nobuko Saigusa ${ }^{7}$, Kentaro Takagi, \\ Huimin Wang ${ }^{9}$ and Natsuko Yoshifuji ${ }^{10}$ \\ ${ }^{1}$ Graduate School of Bioagricultural Sciences, Nagoya University, Nagoya, Japan \\ ${ }^{2}$ Terrestrial Environment Research Center, Tsukuba University, Tsukuba, Japan \\ ${ }^{3}$ National Institute of Advanced Industrial Science and Technology, Tsukuba, Japan \\ ${ }^{4}$ Institute of Applied Ecology, Chinese Academy of Sciences, Shenyang, China \\ ${ }^{5}$ Graduate School of Agriculture, Hokkaido University, Sapporo, Japan \\ ${ }^{6}$ Forestry and Forest Products Research Institute, Tsukuba, Japan \\ ${ }^{7}$ National Institute for Environmental Studies, Tsukuba, Japan \\ ${ }^{8}$ Field Science Center for Northern Biosphere, Hokkaido University, Horonobe, Japan \\ ${ }^{9}$ Institute of Geographic Sciences and Natural Resources Research, Chinese Academy of Sciences, Beijing, China \\ ${ }^{10}$ Graduate School of Agriculture, Kyoto University, Kyoto, Japan
}

\begin{abstract}
:
Evapotranspiration over forest surfaces is mainly constrained by environmental and forest structural components through their influence on surface conductance $\left(G_{s}\right)$ and aerodynamic conductance $\left(G_{a}\right)$. Tower based eddy covariance data from 16 forest sites in East Asia $\left(2^{\circ} \mathrm{S}\right.$ to $64^{\circ} \mathrm{N}$ ) were used to examine the sensitivity of Matsumoto and Nakai models for predicting $G_{s}$ and $G_{a}$, respectively. Daytime dry-canopy data for the growing season were used in this study. Comparisons between model predictions and observed $G_{s}$ and $G_{a}$ showed good agreement, suggesting that the models were suitable for predicting $G_{s}$ and $G_{a}$ with reasonable accuracy. However, the model for $G_{s}$ was unable to predict $G_{s}$ accurately when soil water content was low $(\sim 10 \%)$. In this circumstance, effective soil water content and a more comprehensive method for modelling the soil water content function must be used. $G_{s}$ in East Asia was largely depended on vapour pressure deficit and secondarily on soil water content. $G_{a}$ was largely affected by leaf area index compared with stand density.
\end{abstract}

KEYWORDS Matsumoto-model; Nakai-model; surface conductance $\left(G_{S}\right)$; aerodynamic conductance $\left(G_{a}\right)$; forest; East Asia

\section{INTRODUCTION}

Evapotranspiration (ET) is a major component influencing the global hydrologic process and thus climate. Surface conductance, $G_{s}$, and aerodynamic conductance, $G_{a}$, are important variables for determining the ET over vegetated surfaces (Maximov et al., 2008; Khatun et al., 2011). $G_{s}$ is known to be controlled by several environmental components (e.g., radiation, temperature, vapour pressure deficit, and soil water content) (Matsumoto et al., 2008). $G_{a}$ is governed by wind speed and surface aerodynamic properties, such as roughness length $\left(z_{0}\right)$ and zero-plane displacement $(d)$, which are the functions of forest structural components (e.g., stand density, $\rho_{s}$, and leaf area index, $\left.L A I\right)$ (Nakai et al., 2008). It is therefore important to quantify how different environmental and forest structural components control $G_{s}$ and $G_{a}$ to understand the relationship of ET to these components.

$G_{S}$ is usually calculated using the inverse form of the Penman-Monteith equation (Monteith, 1965), and $G_{a}$ has generally been computed from wind speed and friction velocity based on observed flux data. However, the accurate calculation of $G_{s}$ and $G_{a}$ using flux data is sometimes difficult because of the heterogeneity of the landscape and the large number of controlling factors involved, including climate, plant biophysics, soil properties and topography.

A number of empirical models have been proposed to calculate $G_{s}$ for many stands of various vegetation categories, including grasslands, crops and broadleaved and coniferous forests (e.g., Jarvis, 1976; Ball et al., 1987; Leuning, 1995). On the basis of the Jarvis model, Matsumoto et al. (2008) developed a pooled model of three temperate and two sub-arctic forests that allows the expression of $G_{s}$ in different forests under different climatic zones using a common parameter set.

Many different approaches have been developed to calculate $d$ and $z_{0}$ (e.g., Pinard, 2000; Raupach, 1994; Choudhury and Monteith, 1988). However, existing approaches generally utilise highly simplified representations of vegetation structure. Nakai et al. (2008) proposed a new model to calculate $d$ and $z_{0}$ using forest structure data such as $L A I\left(\mathrm{~m}^{2} \mathrm{~m}^{-2}\right)$ and $\rho_{S}\left(\right.$ trees ha $\left.{ }^{-1}\right)$.

However, the Matsumoto and Nakai models that predict $G_{s}$ and $G_{a}$ are derived from small numbers of measurements. In this study, we compiled the measurement data from 16 forest sites in East Asia to evaluate the effectiveness of the Matsumoto and Nakai models in relation to our data sets. We also examined the dependence of $G_{s}$ and $G_{a}$ on environmental and forest structural components using these

Correspondence to: Rehana Khatun, Lab. of Forest Meteorology and Hydrology, Graduate School of Bioagricultural Sciences, Nagoya University, Japan. E-mail: rehanakhatun_2008@yahoo.co.jp (C2011, Japan Society of Hydrology and Water Resources. 
models. This information will be useful for land surface parameterisation in regional climate simulations, particularly in East Asia.

\section{MATERIALS AND METHODS}

Site description, measurement system, quality control and data selection for turbulent fluxes

Data were collected from 16 forest sites in East Asia that were distributed geographically from $2^{\circ} \mathrm{S}$ to $64^{\circ} \mathrm{N}$ latitude and $98^{\circ} \mathrm{E}$ to $142^{\circ} \mathrm{E}$ longitude (see Figure S1 for the geographic and climatic positions in detail). The study included one tropical rain forest (PDF), four tropical monsoon forests (SKR, MKL, MMP and KMW), one subtropical monsoon forest (QYZ), two warm-temperate forests (SMF and GDK), one temperate forest influenced by the monsoon (CBS), four cool-temperate forests (TMK, MBF, MMF and TSE), and three sub-arctic forests (SKT, YLF and TUR).

An eddy covariance and a meteorological measurement system were used at each site to measure sensible heat flux $(H)$, latent heat flux $(\lambda E)$, friction velocity $\left(u_{*}\right)$ and basic environmental components. The principal investigators performed quality controls at each site. We collected 30and 60-min averages of flux and meteorological data for this study. Data for daytime (net radiation $>0 \mathrm{~W} \mathrm{~m}^{-2}$ ) and dry-canopy conditions (excluding data collected during rainfall events and within $10 \mathrm{~h}$ after these events) for the growing season were used for the analysis. After excluding the wet-canopy data, more than $60 \%$ of daytime data were available for most of the measurement years. To avoid variations in the closure of energy balance among the sites, closure was forced to 1 by the Bowen ratio closure method.

The site description (Table S1), eddy covariance instruments (Table S2) and quality control and data selection for turbulent fluxes (Text S1) are described with more details in the supplements. The calculation of $G_{S}$ and $G_{a}$ based on observed data is described in Text S2.

\section{Estimation of $G_{s}$ and $G_{a}$}

According to the Jarvis-type model (Jarvis, 1976), $G_{S}$ is a function of several environmental variables and is expressed as

$$
G_{s}=G_{\text {smax }} f_{1}(Q) f_{2}(D) f_{3}(T) f_{4}(\theta)
$$

where $G_{\text {smax }}$ is the maximum surface conductance and $f_{1}(Q)$, $f_{2}(D), f_{3}(T)$, and $f_{4}(\theta)$ are the functions of the photosynthetic photon flux density $\left(Q, \mu \mathrm{mol} \mathrm{m} \mathrm{m}^{-2} \mathrm{~s}^{-1}\right)$, vapour pressure deficit $(D, \mathrm{kPa})$, air temperature $\left(T,{ }^{\circ} \mathrm{C}\right)$ and volumetric soil water content $(\theta, \%)$, respectively. Each function represents the influence of that factor on $G_{S}$ and ranged from 0 to 1 .

According to Matsumoto et al. (2008), the functions are expressed as follows:

$$
\begin{aligned}
& f_{1}(Q)=\frac{Q\left(Q_{\max }+k_{1}\right)}{Q_{\max }\left(Q+k_{1}\right)} \\
& f_{2}(D)=\left[\frac{1}{1+\left(D / D_{0.5}\right)^{k_{2}}}\right]\left(1-k_{3}\right)+k_{3}
\end{aligned}
$$

$$
\begin{aligned}
& f_{3}(T) \\
& =\left(\frac{T-T_{\text {min }}}{T_{\text {opt }}-T_{\text {min }}}\right)\left(\frac{T_{\text {max }}-T}{T_{\text {max }}-T_{\text {opt }}}\right)\left(\left(T_{\text {max }}-T_{\text {opt }}\right) /\left(T_{\text {opt }}-T_{\text {min }}\right)\right) \\
& f_{4}(\theta)=\frac{\left(\theta-\theta_{\text {min }}\right)\left(\theta_{\text {max }}-\theta_{\text {min }}+k_{4}\right)}{\left(\theta_{\text {max }}-\theta_{\text {min }}\right)\left(\theta-\theta_{\text {min }}+k_{4}\right)}
\end{aligned}
$$

where $D_{0.5}, T_{\text {min }}, T_{\text {opt }}, T_{\text {max }}, \theta_{\text {min }}$ and $k_{1}-k_{4}$ are the fitting parameters; $Q_{\max }$ and $\theta_{\max }$ are fixed parameters. $T_{\min }, T_{\text {opt }}$ and $T_{\text {max }}$ are the minimum, optimum and maximum $T$ values, respectively; $\theta_{\min }$ and $\theta_{\max }$ are the minimum and maximum $\theta$ values; and $Q_{\max }$ is the maximum $Q$ value. Detailed descriptions of all fitting and fixed parameters were provided by Matsumoto et al. (2008). According to the pooled model, the values of the fitting parameters are $k_{1}=310, k_{2}=3.0$, $k_{3}=0.10, k_{4}=20, D_{0.5}=1.25, T_{\text {min }}=2, T_{\text {opt }}=22, T_{\text {max }}$ $=37$ and $\theta_{\text {min }}=10$ and fixed parameters are $Q_{\max }=2100$ and $\theta_{\max }=50 ; G_{\text {smax }}=0.037 \mathrm{~m} \mathrm{~s}^{-1}$, when $L A I \geq 3 ; G_{\text {smax }}$ $=G_{S M A X}(L A I / 6+0.5)$ when $0<L A I<3$; and $G_{S M A X}$ is the maximum $G_{S}$ with highest $L A I$.

The effects of each variable on the variation of $G_{S}$ were calculated as the contribution of each function $\left(\alpha_{x}=\beta_{x}-\right.$ $\omega_{a}$ ) to modelling accuracy using the root mean-square error (RMSE) value (Matsumoto et al., 2005). $\alpha_{x}$ is the contribution index $\left(\mathrm{m} \mathrm{s}^{-1}\right)$ of one function, i.e., $f(x)$ to the variability of $G_{s}, \beta_{x}$ is the RMSE between the observed and estimated values in which a function for a certain variable was excluded, and $\omega_{a}$ is the RMSE between the observed and estimated values containing all of the functions in Equation (1). More description is in Text S3.

$G_{a}$ was calculated as (Businger, 1956)

$$
\frac{1}{G_{a}}=\left(\operatorname{In} \frac{z-d}{z_{0}}\right)^{2}\left(\frac{1}{k^{2} U_{\mathrm{z}}}\right)
$$

where $z$ is the measurement height $(\mathrm{m}), U_{z}$ is wind speed at height $z\left(\mathrm{~m} \mathrm{~s}^{-1}\right)$, and $k$ is von Karman's constant $(0.40)$.

According to the Nakai et al. (2008) model, $d$ and $z_{0}$ are expressed as

$$
\begin{aligned}
& \frac{d}{h}=1.0-\frac{1.0-\exp \left(-\alpha \rho_{s}\right)}{\alpha \rho_{s}} \frac{1.0-\exp (-\beta L A I)}{\beta L A I} \\
& \frac{z_{0}}{h}=0.264\left(1.0-\frac{d}{h}\right)
\end{aligned}
$$

where $d / h$ and $z_{0} / h$ are the zero-plane displacement and roughness length, respectively, normalised by canopy height $h$, and $\alpha$ and $\beta$ are the fitting parameters.

\section{RESULTS AND DISCUSSION}

\section{Surface conductance}

Figure 1 shows the relationship between growing season mean $G_{s}$ and environmental variables $(Q, T, D$ and $\theta)$. The line represents potential $G_{S}$ calculated by a single fitting function $\left[G_{\text {smax }} \times\right.$ Equation (i); i $=2,3,4$ and 5] and the pooled values of fitted parameters $\left(k_{1}-k_{4}\right)$. The points represent the actual $G_{s}\left(G_{\text {sobs }}\right)$ calculated from the inverse Penman-Monteith equation. Each potential line follows the upper boundary of the actual values, indicating that the 
pooled model clearly expresses the response characteristics of stomata to each variable as of the study of Matsumoto et al. (2005). However, at two sites (SKR and SKT) with low $\theta, G_{\text {sobs }}$ exceeded the potential curve represented by $f(\theta)$. This suggests that $f(\theta)$ could not accurately represent the $G_{\text {sobs }}$ for low-water conditions in the shallow soil layer, whereas the other functions of this model are potentially applicable to our data set.

The linear regression between modelled $G_{s}\left(G_{\text {smod }}\right)$ calculated by the pooled model and $G_{\text {sobs }}$ (Figure 2a) gave a slope of 1.06 with a high level of significance $(P<0.005)$ and RMSE of $0.005 \mathrm{~m} \mathrm{~s}^{-1}$. This result indicates that the pooled model is capable of predicting $G_{s}$. However, the relatively low $R^{2}$ value $(0.51)$ indicates that $G_{\text {smod }}$ did not always fit the calculated value well. This result might be explained by the large underestimation of $G_{S}$ by the pooled model at tropical monsoon site SKR and boreal site SKT and overestimation of $G_{S}$ at cool-temperate sites MMF and TSE.

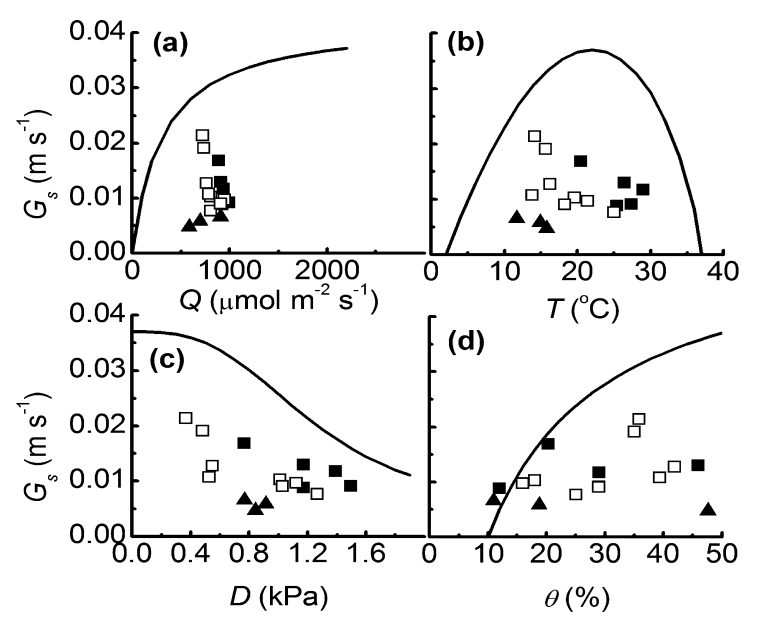

Figure 1. Relationship between surface conductance $\left(G_{S}\right)$ and environmental components: (a) photosynthetic photonflux density $Q$; (b) air temperature $T$; (c) vapour pressure deficit $D$; and (d) soil water content $\theta$. The line represents potential $G_{S}$ calculated by single fitting function, and points represent actual $G_{S}$ calculated from observed data. Closed squares, open squares, and closed triangles indicate tropical, temperate and boreal sites, respectively.
The poor agreement at SKR and SKT might be partially attributable to the use of top layer $\theta$ in calculating the $f(\theta)$. The low water-holding capacity of the sandy soil at SKR and SKT may cause a low-water condition in the top soil layer that greatly affects model values of $G_{s}$. However, $G_{s o b s}$ at these sites was not affected by low $\theta$ (Figure 2). Trees might be able to use deeper soil water when the top layer becomes dry (e.g., Tanaka et al., 2004; Li et al., 2006). On the other hand, the pooled model overestimated $G_{S}$ at two cool-temperate sites (MMF and TSE). At these sites, the $G_{\text {smod }}$ values were approximately double than those of the $G_{\text {sobs }}$. Higher $\theta$ values at these sites resulted in higher $G_{S}$ model output. However, in real situation, $\theta$ had lower impact on the actual $G_{s}$. These sites are belonging to maritime climate and are characterized by low temperature and high humidity resulting in low atmospheric evaporative demand. The lower values of latent heat flux and higher values of Bowen ratio due to low atmospheric evaporative demand might affect the actual $G_{\mathrm{S}}$ (see Equation (1) in Text S2). Without these exceptional four sites, the linear regression between $G_{\text {smod }}$ and $G_{\text {sobs }}$ gave a slope of 0.90 and $R^{2}$ of 0.75 with $P<0.0005$ and RMSE of $0.003 \mathrm{~m} \mathrm{~s}^{-1}$. This high correlation illustrates that in absence of the water stress $(\theta$ $\sim 10 \%)$ condition or high water content $(\theta>40 \%)$ condition with low evaporative demand, the pooled model is suitable for the prediction of $G_{s}$.

Figure $2 \mathrm{~b}$ shows the contribution $\left(\alpha_{x}\right)$ of each function to the variability of $G_{s}$. Among all of the variables, $D$ was the dominant component of variability in $G_{s}$, and the order of $\alpha_{x}$ for each function was $f(D)>f(\theta)>f(Q)>f(T)$. The values of $f(D)$ were reduced by the higher values of $D$ at most of the sites and were a greater controlling factor for $G_{s}$. The exceptions were found at cool-temperate sites, where the values of $f(D)$ were nearly 1 and not a controlling factor for $G_{s}$. At tropical, warm-temperate and some boreal sites, where $\theta<30 \%, f(\theta)$ was the greater controlling factor. The values of $f(Q)$ were $>0.80$ at all sites except two boreal sites. At boreal sites, $G_{S}$ was quite affected by $Q$. At most of the studied sites, $T$ was between $17^{\circ} \mathrm{C}$ and $27^{\circ} \mathrm{C}[f(T)>0.90]$ and did not act as a controlling factor. However, at some cool-temperate and boreal sites, $T$ was between $12^{\circ} \mathrm{C}$ and $15^{\circ} \mathrm{C}$ and exerted a control on $G_{s}$. Therefore, $G_{s}$ in East Asian forests was not directly determined by $Q$ and $T$. Even if the functions of $Q$ and $T$ were excluded from the pooled model, $R^{2}$ and $P$ values became slightly larger than those of the complete model. This was probably the result of the
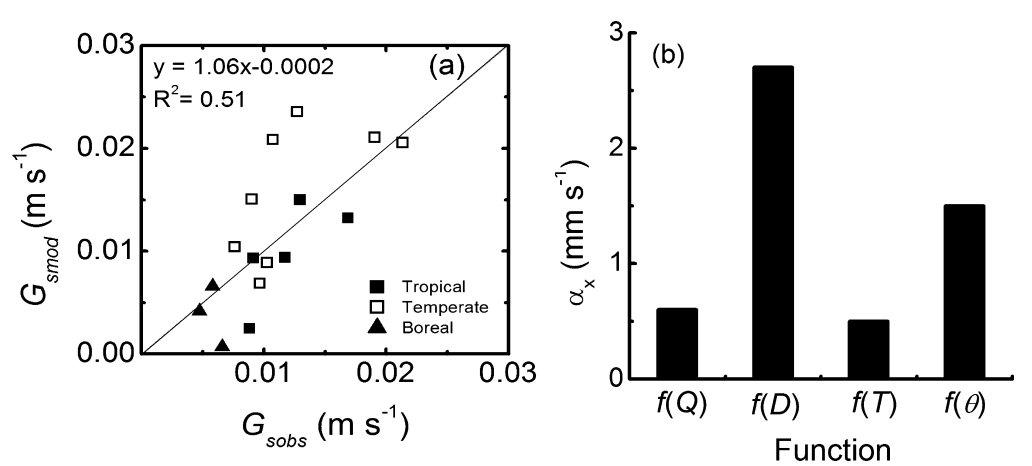

Figure 2. (a) Relationship between estimated $\left(G_{\text {smod }}\right)$ and observed $\left(G_{s o b s}\right) G_{s}$; and (b) relative contributions $\left(\alpha_{x}\right)$ of each environmental function to $G_{S}$ variability. 

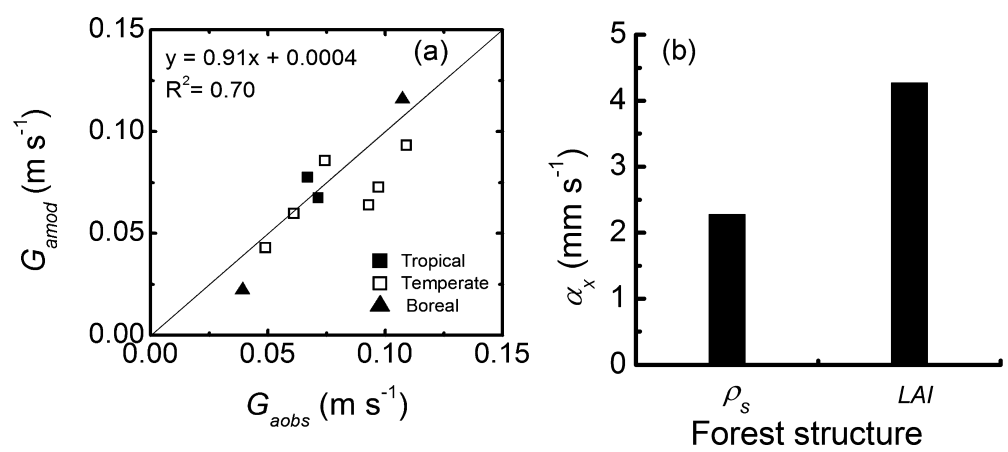

Figure 3. (a) Relationship between estimated $\left(G_{\text {amod }}\right)$ and observed $\left(G_{\text {aobs }}\right)$ aerodynamic conductance $\left(G_{a}\right)$; and (b) relative contributions $\left(\alpha_{x}\right)$ of forest structural components $\left(\rho_{s}\right.$ and $\left.L A I\right)$ to the variability in $G_{a}$.

high correlation between $T$ and $D\left(R^{2}=0.74\right)$, indicating that the effect of $T$ was incorporated into $D$ and the narrow range of growing season mean $Q$ and $T$. However, without the functions of $Q$ and $T$, RMSE was increased, indicating that estimation of $G_{S}$ without these functions was less satisfactory at our sites. Therefore, including all functions in the model enhances the applicability of the model at studied sites. Because of previous studies on the response of $G_{S}$ to environmental components (e.g., Ogink-Hendriks, 1995; Matsumoto et al., 2005) have been limited in terms of latitude ranges, the results of some single-site studies on the response of $G_{S}$ to environmental factors based on seasonal variation have discussed here. In those studies, radiation was the dominant factor for the seasonal variation in $G_{s}$, with results based on hourly values (Ogink-Hendriks, 1995) and daily mean values (Matsumoto et al., 2005) for the growing season. Both hourly and daily mean values can exhibit low radiation that limits $G_{s}$. In our study, the growing season mean values of $Q$ were mostly $>700 \mu \mathrm{mol} \mathrm{m}{ }^{-2} \mathrm{~s}^{-1}$ $[f(Q)>0.80]$ and were not a controlling factor. However, the higher $T$ in the growing season accelerated $D$, which might have greatly determined dry-canopy $G_{s}$.

\section{Aerodynamic conductance}

Normalised displacement height $(d / h)$ (Equation 7), and roughness length $\left(z_{0} / h\right)$ (Equation 8$)$ were calculated for 10 forest sites (Table S1) because of the lack of $\rho_{S}$ and $L A I$ data at other sites. The values of $d$ and $z_{0}$ estimated by Nakai-model ( $d_{\text {mod }}$ and $z_{\text {Omod }}$ ) showed a good agreement with those of observed $d$ and $z_{0}\left(d_{o b s}\right.$ and $\left.z_{0 o b s}\right)$ (Figure S2 and detailed in Text S4). However, the validity test of Nakaimodel for estimating $d$ and $z_{0}$ was limited at six sites only (two tropical, two temperate and two boreal sites) because of the lack of wind profile data at other sites.

$G_{a}$ estimated by Nakai-model $\left(G_{a m o d}\right)$ was compared with observed $G_{a}\left(G_{a o b s}\right)$ calculated by measured friction velocity and wind speed. Linear regression between $G_{\text {amod }}$ and $G_{a o b s}$ (Figure 3a) gave a slope of 0.91 and $R^{2}$ of 0.70 with a high level of significance $(P<0.002)$, and RMSE of $0.015 \mathrm{~m} \mathrm{~s}^{-1}$. This result indicates that the Nakai-model is highly satisfactory for the prediction of $d$ and $z_{0}$, and is thus applicable to the prediction of $G_{a}$.

To quantify the contribution $\left(\alpha_{x}\right)$ of $\rho_{s}$ and $L A I$ to the variability in $G_{a}$, RMSE was calculated between $G_{a o b s}$ and $G_{\text {amod }}$ using the estimated values of $d / h$ and $z_{0} / h$, where $\rho_{s}$ and $L A I$ were excluded from Equation 7 one by one (Text
S5). As shown in Figure 3b, LAI made a larger contribution than did $\rho_{s}$ to the variation in $G_{a}$, because of the close relationship of the roughness parameters $\left(d / h\right.$ and $\left.z_{0} / h\right)$ to $L A I$ compared with $\rho_{s}$, i.e., $d / h$ increased and $z_{0} / h$ decreased clearly with the increase in $L A I$, however, $d / h$ increased and $z_{0} / h$ decreased with the increase in $\rho_{s}$ upto certain limit and after that changing only slightly as $\rho_{s}$ increased (Figure S3).

\section{SUMMARY AND CONCLUSIONS}

Our results indicate that both the Matsumoto and Nakai models can be applied to broad climate and forest types using growing season mean data. However, $G_{S}$ was poorly modelled at extremely low soil water condition ( $\theta$ of approximately $10 \%$ ). The use of appropriate $\theta$ values and a more comprehensive method for modelling the soil water function are needed under this condition. $G_{S}$ depended on the environmental components in the order $D>\theta>Q>T$. The dependence of $G_{a}$ on $L A I$ was higher than that on $\rho_{s}$. This study is the first to predict $G_{s}$ and $G_{a}$ using the Matsumoto and Nakai models in East Asian forests. The results provide useful information for predicting $G_{s}$ and $G_{a}$ and indicate that the estimation of these parameters is possible in the absence of flux data at a larger scale.

\section{ACKNOWLEDGEMENTS}

The data were provided by CREST sites, AsiaFlux sites, ChinaFlux sites, principal investigator of Korean site, Professor Dr. Joon Kim, Seoul National University, Korea. This research was funded by the Core Research for Evolutional Science and Technology (CREST), the Global Water and Energy Cycle Experiment-Asian Monsoon Experiment-Tropics (GEWEX/GAME-Tropics), the Japanese Ministry of the Environment, the Korea Science and Engineering Foundation, and the Japan Society for the Promotion of Science (JSPS).

\section{SUPPLEMENTS}

Supplement 1. This includes:

Table S1. Description of the study sites

Table S2. Measurement system, height, year, closure rate 
and growing season length

Text S1. Description of quality control and data selection for turbulent fluxes

Text S2. Calculation of $G_{a}$ and $G_{S}$ based on observed data

Text S3. Calculation of dependence of $G_{S}$ on environmental components

Text S4. Calculation of zero-plane displacement $(d)$ and roughness length $\left(z_{0}\right)$

Text S5. Calculation of dependence of $G_{a}$ on forest structural components

Figure S1. Locations of the study sites: (a) geographic and (b) climatic (based on the annual sum precipitation and annual mean temperature).

Figure S2. Relationship between: (a) estimated $\left(d_{\text {mod }}\right)$ and observed $\left(d_{o b s}\right)$ zero-plane displacement $(d)$ and (b) estimated $\left(z_{0 \text { mod }}\right)$ and observed $\left(z_{\text {Oobs }}\right)$ roughness length $\left(\mathrm{z}_{0}\right)$.

Figure S3. Relationship between normalized zero-plane displacement $(d / h)$, roughness length $\left(z_{0} / h\right)$ and (a) stand density $\left(\rho_{S}\right)$, (b) leaf area index $(L A I)$.

\section{REFERENCES}

Ball JT, Woodrow IE, Berry JA. 1987. A model predicting stomatal conductance and its contribution to the control of photosynthesis under different environmental conditions. In Progress in Photosynthesis Research, IV, Proceedings of the VII International Congress on Photosynthesis, Biggens, I. (ed.). Martinus-Nijhoff Publishers: Dordrecht, The Netherlands; 221-224.

Businger JA. 1956. Some remarks on Penman's equation for the evaporation. Netherlands Journal of Agricultural Science 4: 77-80.

Choudhury BJ, Monteith JL. 1988. A four-layer model for the heat budget of homogeneous land surfaces. Quarterly Journal of the Royal Meteorological Society 114: 373-398. doi: 10.1002/ qj.49711448006.

Jarvis PG. 1976. The interpretation of the variations in leaf water potential and stomatal conductance found in canopies in the field. Philosophical Transactions of the Royal Society of London. Series B, Biological Sciences 273: 593-610. doi: 10.1098/rstb.1976.0035.

Khatun R, Ohta T, Kotani A, Asanuma J, Gamo M, Han S, Hirano T, Nakai Y, Saigusa N, Takagi K, Wang H, Yoshifuji N. 2011. Spatial variations in evapotranspiration over East Asian forest sites. I. Evapotranspiration and decoupling coefficient. Hydrological Research Letters 5, 83-87. doi: 10.3178/HRL.5.83.

Leuning R. 1995. A critical appraisal of a combined stomatal photosynthesis model for $\mathrm{C} 3$ plants. Plant, Cell and Environment 18: 339-355. doi: 10.1111/j.1365-3040.1995.tb00370.x.

Li SG, Tsujimura M, Sugimoto A, Sasaki L, Yamanaka T, Davaa G, Oyunbaatar D, Sugita M. 2006. Seasonal variation in oxygen isotope composition of waters for a montane larch forest in Mongolia. Trees 20: 122-130. doi: 10.1007/s00468005-0019-1.

Matsumoto K, Ohta T, Tanaka T. 2005. Dependence of stomatal conductance on leaf chlorophyll concentration and meteorological variables. Agricultural and Forest Meteorology 132: 44-57. doi: 10.1016/j.agrformet.2005.07.001.

Matsumoto K, Ohta T, Nakai T, Kuwada T, Daikoku K, Iida S, Yabuki H, Kononov AV, van der Molen MK, Kodama Y, Maximov TC, Dolman AJ, Hattori S. 2008. Responses of surface conductance to forest environments in the Far East. Agricultural and Forest Meteorology 148: 1926-1940. doi: 10.1016/j.agrformet.2008.09.009.

Maximov T, Ohta T, Dolman AJ. 2008. Water and energy exchange in East Siberian forest: A synthesis. Agricultural and Forest Meteorology 148: 2013-2018. doi: 10.1016/ j.agrformet.2008.10.004.

Monteith JL. 1965. Evaporation and environment, in the state and movement of water in living organisms. Symposia of the Society for Experimental Biology 19: 205-234.

Nakai T, Sumida A, Daikoku K, Matsumoto K, van der Molen MK, Kodama Y, Kononov AV, Maximov TC, Dolman AJ, Yabuki H, Hara T, Ohta T. 2008. Parameterisation of aerodynamic roughness over boreal, cool- and warmtemperate forests. Agricultural and Forest Meteorology 148: 1916-1925. doi:10.1016/j.agrformet.2008.03.009.

Ogink-Hendriks MJ. 1995. Modelling surface conductance and transpiration of an oak forest in The Netherlands. Agricultural and Forest Meteorology 74: 99-118. doi:10.1016/01681923(94)02180-R.

Pinard D. 2000. Numerical simulation of wind in plant canopies. Ph.D. Thesis, University of Alberta, Canada.

Raupach MR. 1994. Simplified expressions for vegetation roughness length and zero-plane displacement as functions of canopy height and area index. Boundary-Layer Meteorology 71: 211216. doi: 10.1007/BF00709229.

Tanaka K, Takizawa H, Kume T, Xu J, Tantasirin C, Suzuki M. 2004. Impact of rooting depth and soil hydraulic properties on the transpiration peak of an evergreen forest in northern Thailand in the late dry season. Journal of Geophysical Research 109 (D23): 107. doi: 10.1029/2004JD004865. 